\title{
Vitamin D in Thyroid Disorders
}

Authors

Affiliation

\section{P. Kmieć, K. Sworczak}

Department of Endocrinology and Internal Medicine, Medical University of Gdańsk, Gdańsk, Poland
Key words

vitamin D

- vitamin D deficiency

- calcitriol

- thyroid cancer

- autoimmune thyroiditis

- Graves' disease

- Hashimoto thyroiditis

- hyperthyroidism

hypothyroidism received 23.01.2015

first decision 03.04.2015

accepted $\quad 01.06 .2015$

\section{Bibliography}

DoI http://dx.doi.org/

10.1055/s-0035-1554714

Exp Clin Endocrinol Diabetes

2015; 123: 386-393

(c) J. A. Barth Verlag in

Georg Thieme Verlag KG

Stuttgart · New York

ISSN 0947-7349

Correspondence

Dr. P. Kmiec

Department of Endocrinology

and Internal Medicine

Medical University of Gdańsk

7 Dębinki Street

80952 Gdańsk

Poland

Tel.: + 48/583/492846

Fax: +48/583/492841

piotrkmiec@gmail.com

\section{Abstract}

Vitamin D's canonical role are its effects exerted on the musculoskeletal system. In the last decades the importance of this hormone has been studied in the context of extraskeletal health. Hypovitaminosis D and several polymorphic variants of genes coding proteins crucial in the transport, metabolism and effects of vitamin D have been associated with negative health outcomes.

In this review the current state of knowledge on the role of vitamin $\mathrm{D}$ in thyroid disorders is pre- sented. The review is based on a literature search of the PubMed database performed in December 2014. The following search terms were used in conjunction with 'vitamin D': thyroid cancer, Graves', Hashimoto, thyroiditis, autoimmune thyroid, AITD, nodules, hyperthyroidism, and hypothyroidism.

Currently, similarly to other extraskeletal health outcomes, a clear role of vitamin D has not been demonstrated in thyroid disorders. Further research is necessary to fully elucidate the importance of vitamin $\mathrm{D}$ in case of thyroid disease.

\begin{tabular}{|c|c|c|c|}
\hline \multirow{2}{*}{\multicolumn{2}{|c|}{$\begin{array}{l}\text { Abbreviations } \\
\nabla\end{array}$}} & MIT & monoiodotyrosine \\
\hline & & MNG & multinodular nontoxic goiter \\
\hline $1,25(\mathrm{OH}) 2 \mathrm{D}$ & 1,25-dihydroxyvitamin $\mathrm{D}$, calcitriol & mRNA & messenger ribonucleic acid \\
\hline $24,25(\mathrm{OH})_{2} \mathrm{D}$ & 24,25-dihydroxyvitamin D & n.a. & not available \\
\hline $25(\mathrm{OH}) \mathrm{D}$ & 25-hydroxyvitamin D, calcidiol & NIS & sodium-iodide symporter \\
\hline AITD & autoimmune thyroid disease & PTC & papillary thyroid cancer \\
\hline ATC & anaplastic thyroid cancer & RT-PCR & reverse transcriptase polymerase \\
\hline CYP24A1 & $\begin{array}{l}\text { human gene of cytochrome P450, } \\
\text { family } 24 \text {, subfamily A, polypeptide } 1\end{array}$ & SNP & $\begin{array}{l}\text { chain reaction } \\
\text { single-nucleotide polymorphism }\end{array}$ \\
\hline CYP27B1 & $\begin{array}{l}\text { human gene of cytochrome } \mathrm{P} 450 \text {, } \\
\text { family } 27 \text {, subfamily B, polypeptide } 1\end{array}$ & $\begin{array}{l}\text { TC } \\
\text { TG }\end{array}$ & $\begin{array}{l}\text { thyroid cancer } \\
\text { thyroglobulin }\end{array}$ \\
\hline CYP2R1 & $\begin{array}{l}\text { human gene of cytochrome P } 450 \text {, } \\
\text { family } 2 \text {, subfamily R, polypeptide } 1\end{array}$ & $\begin{array}{l}\mathrm{T} 3 \\
\mathrm{~T} 4\end{array}$ & $\begin{array}{l}\text { triiodothyronine } \\
\text { thyroxine }\end{array}$ \\
\hline DBP & vitamin $\mathrm{D}$ binding protein & $\mathrm{TH}$ & thyroid hormones \\
\hline DHCR7 & $\begin{array}{l}\text { human gene of } 7 \text { - } \\
\text { dehydrocholesterol reductase }\end{array}$ & $\begin{array}{l}\text { TPO } \\
\text { TRAB }\end{array}$ & $\begin{array}{l}\text { thyroid peroxidase } \\
\text { anti-TSH-receptor antibodies }\end{array}$ \\
\hline DIT & diiodotyrosine & TSHR & TSH receptor \\
\hline $\mathrm{DM}$ & diabetes mellitus & TSH & thyroid stimulating hormone \\
\hline DTC & differentiated thyroid cancer & UVB & ultraviolet B \\
\hline FGF23 & fibroblast growth factor 23 & VDR & vitamin $\mathrm{D}$ receptor \\
\hline
\end{tabular}

\section{Introduction}

\section{$\nabla$}

The term 'vitamin D' encompasses several secosteroid compounds; 2 of them, cholecalciferol (or vitamin D3) and ergocalciferol (vitamin D2), are 
commonly referred to with this name. The former is synthesized in the skin upon exposure to ultraviolet B (UVB) radiation by 7-dehydrocholesterol reductase and acquired from few dietary sources (mainly fatty fish), while the latter is synthesized by plants and fungi, which may constitute vitamin D2 dietary source for humans.

Both vitamin D2 and D3 are hydroxylated in the liver to 25-hydroxyvitamin D (25(OH)D, calcidiol), which is the major circulating and storage form of vitamin D. It has little biological activity, however, its serum concentration is universally acknowledged to reflect vitamin D status (Muscogiuri et al. 2014; Prietl et al. 2013). The active hormone is acquired by hydroxylation of 25(OH)D to 1,25-dihydroxyvitamin D $\left(1,25(\mathrm{OH})_{2} \mathrm{D}\right.$, calcitriol). This conversion takes place mainly in the kidney and is regulated by a negative feedback by elevated calcitriol concentrations and fibroblast growth factor 23 (FGF23). However, calcitriol is also synthesized in other cell types (immune cells in particular) as an auto- and paracrine cytokine, without the above regulatory feedback (Prietl et al. 2013). It has been proposed that serum calcidiol level serves as the main determining factor of extrarenal calcitriol synthesis (Jones 2013). Indeed, numerous associations have been found between vitamin D status (reflected by $25(\mathrm{OH}) \mathrm{D}$ serum concentration) and extraskeletal health outcomes, rather than with calcitriol serum concentrations (Jones 2013; Holick 2007). Calcitriol inactivation is mediated by 24-hydroxylase. Calcidiol is bound in $88 \%$ and calcitriol in $85 \%$ with vitamin D binding protein (DBP), $12-15 \%$ of circulating vitamin $D$ analytes are bound to albumin, while it is the free form of sterols that has greater accessibility to target cells (Speeckaert et al. 2006). Calcitriol binds most strongly to the intracellular vitamin $\mathrm{D}$ receptor, VDR, which acts on response elements of target genes to exert its effects.

A number of polymorphic variants of genes involved in metabolism, transport, and activity of vitamin D have been investigated in recent years. Vitamin D receptor gene's variants have been studied most extensively. Four single-nucleotide polymorphic (SNP) variants of the gene: ApaI, BsmI, FokI, and, TaqI, have been examined most frequently and associated with various health outcomes - among them cancers and autoimmune disorders (Xu et al. 2014; D'Aurizio et al. 2014). Other genes, whose variants may lead to altered availability and metabolism of vitamin $\mathrm{D}$ are: DHCR7, GC, CYP2R1, CYP27B1, CYP24A1; they encode proteins mentioned above: 7-dehydrocholesterol reductase, vitamin D binding protein (DBP), 25-hydroxylase, 1-alpha-hydroxylase, and 24-hydroxylase, respectively.

Calcitriol has been long recognized as a crucial hormone in the regulation of the musculoskeletal system. However, extraskeletal effects of $1,25(\mathrm{OH})_{2} \mathrm{D}$ have become focus of intense research in the last decade, after establishing the presence of vitamin $\mathrm{D}$ receptor in nearly all tissue types (Stocklin and Eggersdorfer 2013; Wacker and Holick 2013). VDR is a transcription factor that conveys the vast majority of biological effects of calcitriol. Also, a form of a membrane-bound vitamin $D$ receptor has been hypothesized, which would mediate non-genomic, rapid effects of $1,25(\mathrm{OH})_{2} \mathrm{D}$ (Wacker and Holick 2013).

Regarding thyroid disorders, the antiproliferative and prodifferentiating effects of calcitriol come to play in thyroid tumorigenesis, its role in the modulation of the immune system has been pointed out in autoimmune thyroid disease (AITD). Also, in this review the role of vitamin $D$ in the context of thyroid function, hypo- and hyperthyroidism will be presented in brief.

\section{Aim}

$\nabla$

In this review a summary of the current state of knowledge on the role of vitamin $\mathrm{D}$ in thyroid disorders will be presented.

\section{Methods}

$\nabla$

The review is based on an electronic search of literature in the PubMed database performed in December 2014 using the following search terms: vitamin D thyroid cancer; vitamin D thyroiditis; vitamin D Hashimoto; vitamin D Graves; vitamin D goiter; vitamin D hyperthyroidism; vitamin D hypothyroidism; and vitamin D nodule. Papers were included in the review based on screening of the titles and/or abstracts.

\section{Vitamin D and Thyroid Function}

$\nabla$

The thyroid gland serves as a synthesis, storage and release organ for the thyroid hormones (THs), thyroxine (T4) and triiodothyronine (T3), which are vital for maintaining appropriate function of all tissue and cell types. Their synthesis is stimulated by the thyroid stimulating hormone (TSH) released by the pituitary. Both THs constitute a phenyl ring and a tyrosine molecule; 2 iodine atoms are bound to the tyrosine ring and 2 (in case of T4) or one (T3) iodine atom is linked to the phenyl ring (Ross 2015). Only the thyroid gland produces thyroxine, which constitutes approximately $85 \%$ of both hormones' secretion, while T3 is mainly obtained by deiodination of T4 in peripheral tissues and has a 3- to 8-fold greater biological activity compared to T4; the latter is considered a prohormone (Szczeklik and Augustynowicz-Kopeć 2011). At the microscopic level the thyroid is composed of follicles: follicular cells surround colloid with mostly thyroglobulin ( $\mathrm{Tg}$ ), a glycoprotein that serves as a scaffold for TH production. In brief, iodide - necessary for $\mathrm{TH}$ synthesis - is actively taken up into follicular cells by a transmembrane sodium iodine symporter (NIS) located at the cells' basolateral membrane (Ross 2015). Iodide diffuses to the apical (lumen-neighboring) cellular surface, from where it is transferred into the colloid (at least in part by pendrin, an iodidechloride transporter located in the membrane) (Bizhanova and Kopp 2011). Thyroid peroxidase (TPO) catalyzes oxidation and organification of iodide into tyrosine residues of thyroglobulin, which yields mono- and diiodotyrosine (MIT and DIT, respectively), as well as coupling of 2 DITs into T4 and one MIT with one DIT into T3. TH are secreted into extracellular fluid from follicular cells after endocytosis of colloid droplets, which fuse with lysosomes to enable hydrolysis of Tg to T4, T3 (and aminoacids constituting the protein) (Ross 2015).

Parafollicular C cells are located among or in the wall of thyroid follicles and they secrete calcitonin in the presence of hypercalcemia. The role of this hormone is probably redundant in humans, since calcium-phosphate homeostasis is affected by neither excessive (i.e., in medullary thyroid cancer patients), nor decreased levels of calcitonin (e.g., in post-thyroidectomy patients) (Clinckspoor et al. 2013).

Clinckspoor and co-authors discussed experimental and clinical data on the role of vitamin D in thyroid function in their review paper. In experiments with rodents: high doses of calcitriol did not alter TSH, nor fT4 levels in rats; severely vitamin D-deficient 
diet led to a decrease in TSH but not fT4; in VDR knock-out mice TSH levels were minimally lower - without alteration in thyroid morphology or function. Further, as mentioned by these researchers (and also to our knowledge) no studies examining the effect of vitamin D on thyroid function have been performed, although basal serum TSH levels in subjects with calcidiol lower than or equal to $10 \mathrm{ng} / \mathrm{ml}$ were not significantly different vs. subjects with $25(\mathrm{OH})$ of at least $40 \mathrm{ng} / \mathrm{ml}$ in a cohort study involving inpatients without thyroid disease history (Clinckspoor et al. 2013). Contrasting results were found for: younger men (lowest age tertile of participants aged 15-98) in a randomly selected Thai cohort of 2582 by Chailurkit, Aekplakorn and Ongphiphadhanakul, as well as for middle-aged and elderly Chinese men in a cohort of 9982 persons by Zhang et al. Data gathered by these research groups indicate an association between higher $25(\mathrm{OH})$ D and lower TSH levels (Chailurkit et al. 2013; Q Zhang, Wang and et al. 2014).

Hypothyroidism was associated with hypovitaminosis D by Mackawy, Al-Ayed and Al-Rashidi in their study comprising 30 patients and 30 controls. Respective serum 25(OH)D levels were 14.8 and $44.5 \mathrm{ng} / \mathrm{ml}$; a negative correlation between TSH and calcidiol was found: $r=-0.59$ (Mackawy et al. 2013).

On the other hand, Bouillon, Muls and De Moor reported unaltered calcidiol levels in both hypo- and hyperthyroid patients compared to controls ( $n=23,20$ and 81 respectively). In this study calcitriol was also measured: its increased levels were found in hypothyroid $(73 \mathrm{pg} / \mathrm{ml})$ patients and decreased in hyperthyroid $(28 \mathrm{pg} / \mathrm{ml})$, compared to controls $(43 \mathrm{pg} / \mathrm{ml})$. DBP concentration did not differ between controls and hyperthyroid subjects, and in hypothyroid it was just $17 \%$ higher, which does not account for calcitriol concentration differences (Bouillon et al. 1980).

Unaltered calcidiol and decreased calcitriol levels in untreated hyperthyroidism patients were also reported by Jastrup and colleagues $(n=25)$ as well as MacFarlane and colleagues $(n=21)$ (Jastrup et al. 1982; MacFarlane et al. 1982). Enhanced bone turnover leading to secondary hypoparathyroidism explains the change in $1,25(\mathrm{OH})_{2} \mathrm{D}$.

In regard to parafollicular cells, while in vitro experiments and in vivo studies in rodents demonstrate a negative feedback loop between calcitriol and calcitonin synthesis, important differences exist between humans and rodents in respect to C-cells: in physiological conditions in the former calcitonin is thought to be of no significance. Lack of association between 25(OH)D and calcitonin was shown in the same Belgian hospital patient cohort as mentioned above. After excluding several groups of patients (proton pump inhibitor users, those with renal failure, known thyroid or parathyroid disease) no significant differences were recorded in calcitonin levels between subjects with low and high vitamin D status (defined as above) (Clinckspoor et al. 2013).

\section{Vitamin D and Thyroid Cancers}

$\nabla$

\section{Vitamin D status and thyroid cancer}

A hypothesis of a protective effect of vitamin D against noncutaneous cancers has been put forward (Bikle 2014); vitamin D deficiency, reflected by suboptimal calcidiol concentrations, has been proposed as an important cancer risk factor (Wacker and Holick 2013; Pludowski et al. 2013).

In case of thyroid cancers (TCs) specifically, several reports indicate no significant differences in vitamin $\mathrm{D}$ status between cancer patients and controls. Laney and colleagues found that $25(\mathrm{OH}) \mathrm{D}$ concentrations lower than $30 \mathrm{ng} / \mathrm{ml}$ were not different between the following groups: 45 thyroid cancer patients in remission, 24 patients with an active thyroid cancer and 42 thyroid nodule patients. Of note, vitamin D deficiency prevalence in these groups was higher (at 48-58\%) than that among healthy controls examined in an earlier study at the same institution (32\%) (Laney et al. 2010). Jonklaas, Danielsen and Wang investigated 65 euthyroid patients prior to thyroidectomy (48 with cancer, 17 with a benign thyroid disease) and found that vitamin $\mathrm{D}$ status was not associated with a thyroid cancer diagnosis, nor the disease stage among cancer patients (Jonklaas et al. 2013). LizisKolus and colleagues found similar prevalence of suboptimal calcidiol concentrations in 40 female papillary thyroid cancer (PTC) patients and 40 female Hashimoto thyroiditis patients (Lizis-Kolus et al. 2013).

Contrasting data were reported by other groups. Sahin and coworkers recorded vitamin D deficiency (calcidiol $<20 \mathrm{ng} / \mathrm{ml}$ ) in $71 \%$ of PTC patients (166 out of 235), but only in $59 \%$ of controls (64/108) (Sahin et al. 2013). Roskies and co-authors reported an association between malignancy and vitamin D deficiency (preoperative calcidiol levels lower than $15 \mathrm{ng} / \mathrm{ml}$ ) in patients undergoing thyroidectomy at a thyroid cancer center in Montreal: 9 out of 12 differentiated thyroid cancer (DTC) patients were vitamin D deficient compared to 33 out of 88 thyroid nodule patients (Roskies et al. 2012). Kim and colleagues studied 548 women undergoing thyroidectomy for PTC. Among these subjects significantly lower preoperative vitamin $\mathrm{D}$ concentrations were found in patients with a tumor sized over $1 \mathrm{~cm}$ or with lymph node involvement (Kim et al. 2014). Penna-Martinez and colleagues found an association between DTC and low calcidiol in patients with certain CYP24A1 haplotypes (Penna-Martinez et al. 2012) ( Table 1).

Table 1 Studies examining vitamin D status in thyroid cancer patients.

\begin{tabular}{|c|c|c|c|}
\hline Authors & Study subjects & $\%$ female & 25(OH)D level [ng/ml] \\
\hline Laney et al., 2010 & TC patients: 24 active, 45 in remission; 42 nodular goiter patients & 85 & not different between groups \\
\hline Jonklaas et al. 2013 & $48 \mathrm{TC}$ and 17 nodular goiter patients & 71 & not different between groups \\
\hline Lizis-Kolus et al., 2013 & 40 PTC and 40 Hashimoto thyroiditis patients & 100 & not different between groups \\
\hline Sahin et al., 2013 & 344 PTC patients and 116 healthy controls & 84 & 17 (PTC) vs. 19.1 (significant) \\
\hline Roskies et al., 2012 & 100 patients who underwent total or completion thyroidectomy & 87 & $\begin{array}{l}\text { malignant disease in: } 9 / 12 \text { subjects with } 25(\mathrm{OH}) \\
\mathrm{D}<15,33 / 88 \text { subjects with } 25(\mathrm{OH}) \mathrm{D} \geq 15\end{array}$ \\
\hline Kim et al., 2014 & 548 PTC patients who underwent total thyroidectomy & 100 & $\begin{array}{l}\text { significantly lower among patients with tu- } \\
\text { mors }>1 \mathrm{~cm} \text { or with lymph node metastases }\end{array}$ \\
\hline
\end{tabular}


In respect to vitamin D supplementation, Zhang and co-authors state in their recent review that conclusive data are not available currently to support a positive or negative effect of supplementing vitamins on thyroid cancerogenesis (LR Zhang et al. 2013; Morand et al. 2014). In contrast, thyroid cancer incidence and mortality has been inversely correlated with solar UVB radiation (Morand et al. 2014; Grant 2008; Grant 2012).

\section{Calcitriol and vitamin D signaling in thyroid cancer}

As mentioned above, calcitriol is the active form of vitamin D, which, among all vitamin $\mathrm{D}$ forms, exerts the most of biologic effects by binding to VDR. Consequently, the enzymes: 1-aphahydroxylase (CYP27B1), which catalyzes the conversion of calcidiol to calcitriol, and 24-hydroxylase (CYP24A1), calcitriol inactivating enzyme, are crucial in governing the availability of active vitamin D (Clinckspoor et al. 2013). Also, understandably, the effects of calcitriol depend on VDR, whose polymorphic variants have been studied to a limited extent in case of thyroid cancer.

In 3 studies decreased serum $1,25(\mathrm{OH})_{2}$ D concentrations in thyroid cancer patients compared to controls were reported. In neither of these did 25(OH)D serum concentrations differ between studied subject population samples (Penna-Martinez et al. 2009; Penna-Martinez et al. 2012; Stepien et al. 2010). The group led by Penna-Martinez found this result by investigating sera of PTC and follicular TC (FTC) patients (132 and 40 respectively in the 2009 study, and, 173 and 38 in the 2012 study) vs. healthy controls (321 and 104, respectively).Stępień and colleagues included 27 PTC, 16 FTC, 7 anaplastic thyroid cancer (ATC), 34 multinodular nontoxic goiter (MNG) patients and 26 healthy volunteers in their study. In all cancer cases calcitriol concentration was decreased, its level was lowest in ATC subjects. Also, 1,25(OH $)_{2} \mathrm{D}$ concentrations were cancer-stage dependent: the more advanced the stage, the lower the concentration (Stepien et al. 2010). The significance of the decreased calcitriol concentration is difficult to interpret taking into account the fact that while in vitro experiments prove antiproliferative effects of the hormone, the doses required to observe these are 2-3 orders of magnitude higher than those recorded in vivo in human blood sera (W Liu et al. 2002; Clinckspoor et al. 2011).

Apart from calcitriol levels, VDR gene polymorphisms were analyzed in the study mentioned above by Penna-Martinez and coauthors. ApaI, TaqI, BsmI and FokI SNPs were investigated. Protection against (i.e., lower incidence of) FTC was associated with alleles AA and FF of the ApaI and FokI polymorphic variants, as well as haplotype tABF, while increased risk for FTC with haplotype Tabf (Penna-Martinez et al. 2009). In another report, Sharma and colleagues treated several lines of thyroid cancer cells with VDR agonists and found that the FF FokI genotype was associated with relative resistance to these chemical compounds (Sharma et al. 2010).

Khadzkou and co-authors reported increased VDR and 1-alphahydroxylase expression in PTC cells compared to normal thyroid follicular cells by immunohistochemical staining of tissue specimens of 35 patients ( 26 female). Significantly lower VDR immunoreactivity was recorded in PTC metastases. These findings point at a favorable prognosis of PTC provided VDR and 1-alphahydroxylase expression is increased (Khadzkou et al. 2006).

In line with the function of inactivating vitamin $\mathrm{D}$, increased levels of 24-hydroxylase were associated with unfavorable characteristics of thyroid cancer. Zou and colleagues reported that CYP24A1 overexpression indicated a poor prognosis for PTC based on enzyme's gene expression measured by real-time RT-
PCR in tissue specimens of 60 patients (Zou et al. 2014). The same was corroborated by Balla and co-workers who examined CYP24A1 expression by real-time quantitative PCR in normal and cancer tissue sections of 100 patients with PTC: tumor malignity variables (i.e., vascular invasion, lymph node involvement, tumor size, and hypothyreosis) correlated with CYP24A1 expression (Balla et al. 2014). Resistance to calcitriol (and another VDR agonist) was observed in cells with high baseline 24-hydroxylase mRNA levels by Sharma and co-workers (Sharma et al. 2010). Certain haplotypes of CYP24A1 were associated with decreased calcitriol concentrations in a study by PennaMartinez and others (Penna-Martinez et al. 2012).

Clinckspoor and colleagues studied protein (by immunohistochemistry) and gene expression (with real-time quantitative RTPCR) of VDR, CYP24A1 and CYP27B1 in normal thyroid, follicular adenoma and primary thyroid cancer tissue specimens from 72 patients. In DTC and adenoma the 3 proteins' mRNA expression was increased compared to normal thyroid tissue. In PTC tissues of patients who had lymph node metastases VDR and CYP24A1 expression was lower than in specimens from PTC cases without lymph node involvement. ATC tissue specimens often lacked VDR expression and in high mitotic index ATC tumors (Ki67 over 30\%) more specimens without VDR, CYP24A1 and CYP27B1 immunoreactivity staining were present (Clinckspoor et al. 2012).

As summarized by this Belgian group in a recent review, data on calcitriol signaling in thyroid cancer to date indicate that local antitumor effects are mediated by this hormone. In thyroid tumors cellular/tissue sensitivity to calcitriol depends on CYP24A1 expression, which may be regarded as a marker thereof. Moreover, in vitro studies on thyroid cancer cell lines have shown antiproliferative and prodifferentiating effects of calcitriol and its non-calcemic analogues (among others by Clinckspoor and coworkers) (Clinckspoor et al. 2013). Further, in vitro experiments with combined calcitriol and other antineoplastic drugs (mainly taxanes) treatment in thyroid cancer cells resulted in additional and/or synergistic effects of the drugs (Clinckspoor et al. 2013). These findings provide perspectives for the possibility of future treatment using VDR signaling in thyroid cancer ( $\bullet$ Fig. 1).

\section{Vitamin D and Autoimmune Thyroid Disease}

$\nabla$

Vitamin D modulates the immune system by exerting vital effects on most of its cells. Vitamin D receptor is expressed by

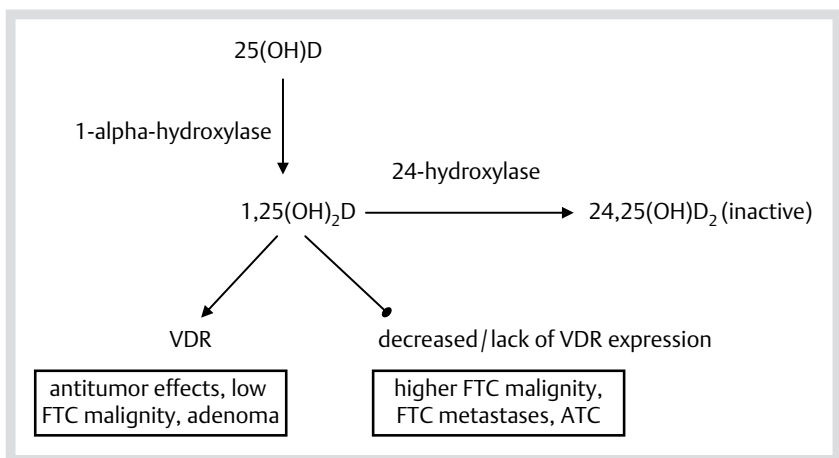

Fig. 1 Local vitamin D signaling in thyroid neoplasms. Studies indicating presented effects are discussed in the text. CYP24A1 expression (gene encoding 24-hydroxylase) in thyroid tumors may be considered a marker of sensivity to calcitriol. ATC - anaplastic thyroid cancer, FTC - follicular thyroid cancer. 
lymphocytes, antigen-presenting cells (e.g., dendritic cells), and macrophages. Calcitriol regulates inflammatory cytokine production and inhibits the proliferation of proinflammatory cells (Yin and Agrawal 2014). The innate immune system is activated by vitamin $D$, which has been demonstrated by hormone's effect on monocytes and macrophages in particular. An opposite, inhibitory, effect has been shown for the acquired immune response (Bouillon 2014), which results in an enhanced tolerance of this system (Bizzaro and Shoenfeld 2015). The latter immunomodulatory effect of vitamin $\mathrm{D}$ has led to investigating its role in a number of autoimmune diseases, which have been associated with hypovitaminosis D (Bizzaro and Shoenfeld 2015; Effraimidis and Wiersinga 2014). Several observations have been made in regard to autoimmune thyroiditis.

In an animal in vivo autoimmune thyroiditis model, CBA strain (general purpose) mice were sensitized with porcine thyroglobulin and treated intraperitoneally with calcitriol at subtherapeutic doses, i. e., $0.1-0.2$ micrograms per kg body weight daily. This treatment led to a reduction in the severity of inflammatory lesions in the gland (Fournier et al. 1990). The incidence of thyroiditis was lower in animals which were treated with both calcitriol and cyclosporine A (subtherapeutic doses) (Fournier et al. 1990; Chen et al. 2002). In another study, female Wistar rats, also sensitized with porcine thyroglobulin, were given calcitriol by intraperitoneal injection ( 5 micrograms per kg every $48 \mathrm{~h}$ ) prior to or following immunization. In the treated animals the thyroid appeared intact, which contrasted with typical inflammatory changes of the thyroid in the placebo group (S Liu et al. 2010).

Choi et al. reported an association among premenopausal women between lower 25(OH)D levels and AITD (i.e., those with positive anti-thyroid peroxidase, anti-TPO, antibodies) in a cross-sectional study involving approximately 6700 participants aged $25-80,42 \%$ female. Mean calcidiol concentrations were $22 \mathrm{vs.} 23.5 \mathrm{ng} / \mathrm{ml}$. This association was not found among postmenopausal subjects. Among all women a trend was also recorded for increasing TPO antibody prevalence and decreasing calcidiol concentrations $(12 \%$ in subjects with $25(\mathrm{OH}) \mathrm{D}$ greater than $30 \mathrm{ng} / \mathrm{ml}, 15.5 \%$ for the $10-20 \mathrm{ng} / \mathrm{ml}$ range, $21 \%$ in subjects with $25(\mathrm{OH}) \mathrm{D}$ lower than $10 \mathrm{ng} / \mathrm{ml}$ ) (Choi et al. 2014). In a report by Shin and co-workers lower 25(OH)D levels in anti-TPO positive subjects were found, mean values were 12.6 (anti-TPO-positive) vs. $14.5 \mathrm{ng} / \mathrm{ml}$ (negative). Further, a weak negative correlation between serum TPO antibodies and 25(OH)D levels $(r=-0.25)$ was found by this group among 304 subjects who were enrolled in an endocrinology outpatient clinic (Shin et al. 2014). Unal and colleagues enrolled newly diagnosed Hashimoto's thyroiditis (HT) (254) and Graves' disease (GD) (27) patients as well as age-matched healthy controls. $25(\mathrm{OH}) \mathrm{D}$ differed significantly between these 3 groups: 14.9 vs. 19.4 vs. $22.5 \mathrm{ng} / \mathrm{ml}$ (Unal et al. 2014). In another study, vitamin D status was compared between endocrine ambulatory AITD patients $(n=50)$, non-AITD ones $(n=42)$, and healthy age-matched controls $(\mathrm{n}=98)$. Vitamin D deficiency (25(OH)D level equal to or lower than $10 \mathrm{ng} / \mathrm{ml}$ ) was found in $72 \%$ ( $79 \%$ for Hashimoto's thyroiditis, or HT, $64 \%$ for Graves' disease, GD), $52 \%$, and $30 \%$ of respective subject groups. Among patients, vitamin D deficiency was more common in those with anti-thyroid antibodies (43 vs. 17\%) (Kivity et al. 2011).

On the other hand, after correction for age and sex no correlation was found between calcidiol and anti-TG antibodies among 2582 randomly selected Thai subjects aged 15-98 (Chailurkit et al. 2013; Effraimidis and Wiersinga 2014). Also, in a community based study in Delhi where 642 students, teachers and staff were enrolled, only a very weak correlation between serum $25(\mathrm{OH}) \mathrm{D}$ and anti-TPO antibody titers was found $(\mathrm{r}=-0.08)$ after results were adjusted for age (Goswami et al. 2009). In another report, 67 subjects from the Amsterdam AITD cohort, i.e., firstand second-degree relatives of overt AITD patients, developed anti-thyroid antibodies during a 5-year follow-up. However, their vitamin $\mathrm{D}$ status did not differ from that of healthy controls. Moreover, in this study, seronegative cohort cases had higher 25(OH)D levels than age-matched controls without AITD family history (Effraimidis et al. 2012). Furthermore, no significant difference in vitamin D levels was found between 2 DM type 1 patients aged $10-19$, i.e., study participants with and without thyroid-specific autoantibodies ( $\mathrm{n}=19$ for both) (Demir et al. 2014) (० Table 2).

The risk of AITD according to VDR gene polymorphisms was summarized in a recent meta-analysis including 8 studies (5 European, 2 Asian, and 1 African). Authors conclude that a decrease in AITD risk is associated with BsmI or TaqI polymorphisms, and, that Apal or FokI polymorphisms are not significantly associated with AITD risk (Feng et al. 2013; Effraimidis and Wiersinga 2014).

In a more recent original paper higher frequencies of $C$ alleles of the ApaI polymorphism, and, CC genotype and C allele of the FokI polymorphism were recorded in AITD patients compared to controls (Inoue et al. 2014). Apart from 4 polymorphic variants of the VDR gene, 2 of GC, and one of CYP2R1 were investigated by Inoue and co-authors among 139 Graves' disease, 116 Hashimoto's thyroiditis patients and 76 control subjects. Regarding both diseases: a higher frequency of the $\mathrm{C}$ allele for the TaqI VDR polymorphism was found in Graves' compared to Hashimoto's disease patients; and a higher frequency in Hashimoto's compared to Graves' disease patients and controls for the CC variant of the FokI VDR polymorphism (Inoue et al. 2014).

Promoter polymorphism of the CYP27B1 gene was analyzed by Lopez and others. In their study 139 HT and 334 GD patients were enrolled, along with 320 controls. An allelic variation was associated with both autoimmune diseases (Lopez et al. 2004).

In a report by Pani and colleagues, an intron 8 DBP gene polymorphism was associated with Graves' disease but not Hashimoto's thyroiditis. In their study 561 Caucasian-origin individuals (respectively 95 and 92 pedigrees) were genotyped for 3 polymorphisms of the gene (Pani, Regulla, Segni, Hofmann et al. 2002).

Also, as concluded by the same research group, based on their analysis of respectively 106 and 92 patients no association was apparent between CYP1- $\alpha$ intron 6 polymorphism and Graves' disease or Hashimoto's thyroiditis (Pani, Regulla, Segni, Krause et al. 2002).

\section{Vitamin D and Hashimoto's thyroiditis}

Regarding vitamin D status and Hashimoto's thyroiditis, Bozkurt and co-workers reported correlations between 25(OH)D concentrations and: thyroid volume $(r=0.15)$, as well as anti-TPO $(r=-0.36)$ and anti-TG $(r=-0.34)$ levels. In their study $180 \mathrm{HT}$ euthyroid patients, 180 newly-diagnosed HT subjects and 180 healthy controls were enrolled. Calcidiol levels lower than $10 \mathrm{ng} /$ $\mathrm{ml}$ were recorded in $48.3,35$ and $20.5 \%$ of subjects respectively (Bozkurt et al. 2013). In another report, vitamin D deficiency prevalence was significantly higher in children with HT $(n=78)$ than in healthy controls $(\mathrm{n}=74)$, i.e., 73 vs. $17.6 \%$. Patients' calcidiol concentrations inversely correlated with anti-TPO levels 
Table 2 Studies examining vitamin D status and autoimmune thyroid disease.

\begin{tabular}{|c|c|c|c|}
\hline Authors & Study subjects & $\%$ female & 25(OH)D level [ng/ml] \\
\hline Choi et al., 2014 & cross-sectional study, $\mathrm{n}=6700$ & 42 & 22 in anti-TPO(+) vs. 23.5 in anti-TPO(-) premenopausal women \\
\hline Shin et al. 2014 & 304 endocrine clinic outpatients & 88 & 12.6 in anti-TPO(+) vs. 14.5 in anti-TPO(-) subjects; \\
\hline Kivity et al., 2011 & $\begin{array}{l}50 \text { AITD and } 42 \text { non-AITD endocrine clinic outpa- } \\
\text { tients; } 98 \text { healthy controls }\end{array}$ & 77 & $\begin{array}{l}<10 \text { in } 79 \% \text { of HT, } 64 \% \text { of GD, } 52 \% \text { of non-AITD patients, and, } \\
30 \% \text { of controls }\end{array}$ \\
\hline Chailurkit et al., 2013 & randomly selected 2582 subjects & 50 & did not correlate with anti-TG levels \\
\hline Goswami et al., 2009 & $\begin{array}{l}642 \text { students, teachers and staff of } 4 \text { schools and a } \\
\text { medical college }\end{array}$ & 62 & not different between anti-TPO $(+)$ and $(-)$ subjects \\
\hline Unal et al., 2014 & $\begin{array}{l}\text { newly-diagnosed: } 254 \mathrm{HT} \text { and } 27 \text { GD patients; } 124 \\
\text { healthy controls }\end{array}$ & 89 & $\begin{array}{l}14.9 \text { vs. } 19.4 \text { vs. } 22.5 \text { (significant); correlated with anti-TPO } \\
(r=-0.18) \text { and }-\mathrm{TC}(-0.14)\end{array}$ \\
\hline Bozkurt et al., 2013 & $\begin{array}{l}180 \text { newly-diagnosed and } 180 \text { euthyroid HT } \\
\text { patients; } 180 \text { healthy controls }\end{array}$ & 68 & $\begin{array}{l}<10 \text { in } 48 \%, 35 \% \text { and } 21 \% \text { of respective subjects; correlated with } \\
\text { anti-TPO }(r=-0.36) \text { and anti-TC antibodies }(-0.34)\end{array}$ \\
\hline Camurdan et al., 2012 & 78 children with $\mathrm{HT}, 74$ healthy controls & n.a. & $\begin{array}{l}\text { deficiency in } 73 \% \text { (patients) vs. } 18 \% \text { (controls); calcidiol corre- } \\
\text { lated with anti-TPO levels among patients ( } r=-0.3 \text { ) }\end{array}$ \\
\hline Mansournia et al., 2014 & $\begin{array}{l}41 \text { hypothyroid } \mathrm{HT} \text { patients and } 45 \text { healthy } \\
\text { controls }\end{array}$ & n.a. & $\begin{array}{l}\text { was inversely associated with } \mathrm{HT} \text { (OR: } 0.81 \text { for } 5 \mathrm{ng} / \mathrm{ml} \text { increase } \\
\text { in } 25(\mathrm{OHD}) \text { ) }\end{array}$ \\
\hline Zhang et al., 2014 & $\begin{array}{l}35 \mathrm{TRAB}(+) \text { and } 35 \mathrm{TRAB}(-) \mathrm{GD} \text { patients; } 70 \\
\text { healthy controls }\end{array}$ & 60 & $\begin{array}{l}<20 \text { in respectively } 65,20 \text { and } 17 \% \text { of subjects; correlated with } \\
\text { TRAB titer } r=-0.5\end{array}$ \\
\hline Yasuda et al., 2013 & $\begin{array}{l}\text { GD patients: } 18 \text { in and } 36 \text { not in remission; } 49 \\
\text { healthy controls }\end{array}$ & 100 & respectively $15.5,18.2$, and 18.6 (significant) \\
\hline Yasuda et al., 2012 & 36 newly-diagnosed GD patients; 46 controls & 100 & 14.4 vs. 17.1 (significant); correlated with TRAB titer $r=-0.45$ \\
\hline
\end{tabular}

$(r=-0.3)$ (Camurdan et al. 2012). Mansournia and colleagues enrolled 41 hypothyroid HT patients and 45 healthy controls and reported an inverse association between 25(OH)D concentration and HT risk; the patients to controls ratio of geometric means of calcidiol concentrations was 0.66 (Mansournia et al. 2014).

Concerning VDR genetic variants, in brief, FokI SNP polymorphism was associated with HT in Japanese females (study involved 130 patients and 150 controls) and Taiwanese Chinese subjects (109 HT subjects including 9 men, 90 controls) (Ban et al. 2001; Lin et al. 2006); BsmI polymorphism, BsmI-TaqI bT haplotype, as well as, baT and BaT extended BsmI-ApaI-TaqI haplotypes were associated with HT in a study comprising 145 patients and 145 healthy controls from the Croatian population (Stefanic et al. 2005); TaqI TT and FokI FF genotypes were significantly more common in HT patients $(n=111)$ than healthy controls $(n=159)$ in Turkey (Yazici et al. 2013). Results concerning associations between HT and polymorphic variants of other genes vital in vitamin D metabolism were mentioned above.

\section{Vitamin D and Graves' disease}

Vitamin D status reported in 35 GD patients with anti-TSHreceptor antibodies (TRABs) was significantly lower than in 35 seronegative GD patients and 70 healthy controls in a study by Zhang, Liang, and Xie. 25(OH)D concentration $<20 \mathrm{ng} / \mathrm{ml}$ was recorded in respectively ca. 65,20 , and $17 \%$ of subjects. An inverse correlation between TRAB titer and 25(OH)D level was found: $r=-0.5$ (H Zhang and Liang and et al. 2014).

Yasuda and colleagues enrolled female GD patients: 18 in remission (defined as euthyroid status for more than a year after discontinuing anti-thyroid drugs) and 36 without remission (discontinuing ant-thyroid drugs was unattainable 4 years after therapy initiation, TRABs were present), as well as 49 healthy controls (with normal thyroid function, without anti-TPO and -TG antibodies). Mean 25(OH)D levels were 14.5, 18.2, and $18.6 \mathrm{ng} / \mathrm{ml}$ (with significant differences), respectively (Yasuda et al. 2013). The same research group also reported a correlation between serum calcidiol level and thyroid volume in newly- diagnosed female Graves' disease patients $(n=26$, all were hyperthyroid and TRAB-positive): $r=-0.45$. Patients' mean 25(OH)D was significantly lower compared to 46 controls (14.4 vs. $17.1 \mathrm{ng} / \mathrm{ml}$ ) (Yasuda et al. 2012).

Kawakami-Tani and co-authors performed an intervention study among Graves' disease patients, who were randomly assigned to receive methimazole with or without vitamin $\mathrm{D}$ ( $\mathrm{n}=15$ for both groups). Subjects receiving vitamin $\mathrm{D}$ achieved euthyroidism faster (Kawakami-Tani et al. 1997). However, farreaching conclusions cannot be drawn from this report not only due to the small sample size, but also several other methodological restrictions (Rotondi and Chiovato 2013).

Regarding genetic studies, in a meta-analysis from 2009 accumulated data pointed at an association of ApaI, BsmI and FokI VDR gene polymorphisms and GD in Asians, and no association of the ApaI, BsmI, TaqI and FokI variants with GD among Caucasians (Zhou et al. 2009); in an Egyptian population findings were the same as for Asian subjects (Abd El Gawad et al. 2012). In 2 studies DBP gene polymorphisms were associated with GD: results of Pani and co-workers were mentioned above (Pani, Regulla, Segni, Hofmann et al. 2002); Kuryłowicz and colleagues enrolled 332 Polish patients and 185 healthy controls and found that susceptibility to GD was associated with Lys allele at codon 420 of this gene (but not with the codon 416 SNP nor variable repeat (TAAA)N polymorphism in intron 8 ), which also correlated with lower calcidiol concentration (Kurylowicz et al. 2006). In a study mentioned above, Inoue and colleagues also noted lower frequencies of one genetic variant of the GC and one of the CYP2R1 gene in intractable GD patients (Inoue et al. 2014). In a Polish population comprising 326 patients and 175 controls, Kuryłowicz and Badenhoop reported an association with GD of the same CYP27B1 gene promoter SNP $(1260 \mathrm{C})$ as Lopez and colleagues (Kurylowicz and Badenhoop 2005; Lopez et al. 2004).

\section{Vitamin D and postpartum thyroiditis}

Krysiak, Kowalska and Okopień studied 4 groups of non-lactating women: hypothyroid $(n=14)$ and euthyroid $(n=14)$ subjects with postpartum thyroiditis, participants with non-autoim- 
mune hypothyroidism $(\mathrm{n}=16)$, and an euthyroid group without thyroid autoimmunity $(n=15)$. Serum $25(\mathrm{OH})$ D concentrations among thyroiditis patients were lower than in the remaining subjects, as well as lower in hypo- than euthyroid women (respective means of the 4 groups: $18,30,38$ and $53 \mathrm{ng} / \mathrm{ml}$ ). Further, anti-TPO and anti-TG antibody titers correlated with calcidiol levels ( $\mathrm{r}$ coefficients in the range of -0.22 to -0.34 ). Hypothyroid subjects were treated with L-thyroxine, however, researchers observed an increase in calcidiol levels only in postpartum thyroiditis patients (thyroid function improved in both groups that required treatment). A correlation between $25(\mathrm{OH}) \mathrm{D}$ levels after thyroxine treatment and antibody titers was recorded too $(r=-0.3$ and -0.2 for respectively anti-TPO and anti-TG). Authors mention the major limitations of their results, among them the low number of subjects, no significant difference in calcidiol levels between groups after taking into account the season of sample collection (Krysiak et al. 2014).

\section{Conclusions}

$\nabla$

The importance of extraskeletal effects of vitamin D have been studied extensively (Bouillon 2014; Schottker et al. 2013; Pludowski et al. 2013; Wacker and Holick 2013). As can be drawn from this review, research on vitamin $\mathrm{D}$ and thyroid disorders too has underlined hormone's significance - particularly in case of gland's cancers and autoimmune diseases. Still, in many points accumulated data are inconclusive, many unresolved questions remain, therefore, it remains necessary to perform further studies that would affect clinical approaches to thyroid disease.

Studies demonstrating associations of hypovitaminosis D with AITD and basic research rationale underlying this relation might lead to recommendations of vitamin D supplementation for the patients, however, currently such treatment is still controversial (Bizzaro and Shoenfeld 2015). Also, at this point, clinical choices are not dependent on possible associations between thyroid disease and genetic variants of VDR and other proteins important in vitamin D metabolism and transport. Applying antineoplastic effects of calcitriol in a clinical setting remains a possible future perspective. Currently, in the context of thyroid disease, but also in a broader perspective, no highly convincing data for any health outcome are available. Moreover, vitamin D supplementation has not affected disease occurrence in intervention studies, as summarized in 2 recent reviews. The associations between vitamin D deficiency and disease may indicate that 25(OH)D is only a marker of ill health (Theodoratou et al. 2014; Autier et al. 2014).

\section{Conflict of interest: None.}

\section{References}

1 Abd El Gawad SS, Abdul Samee ER, Metwali AA et al. Vitamin D receptor gene polymorphism and its association with 1,25-dihydroxyvitamin $\mathrm{D}(3)$ in patients with Graves disease in an Egyptian population: a pilot study. Endocr Pract 2012; 18.2: 132-139

2 Autier P, Boniol M, Pizot C et al. Vitamin D status and ill health: a systematic review. Lancet Diabetes Endocrinol 2014; 2.1: 76-89

3 Balla B, Tobias B, Kosa JP et al. Vitamin D-neutralizing CYP24A1 expression, oncogenic mutation states and histological findings of human papillary thyroid cancer. J Endocrinol Invest 2014

4 Ban Y, Taniyama M, Ban Y. Vitamin D receptor gene polymorphisms in Hashimoto's thyroiditis. Thyroid 2001; 11.6: 607-608

5 Bikle DD. Vitamin D and cancer: the promise not yet fulfilled. Endocrine $2014 ; 46.1$ : 29-38
6 Bizhanova A, Kopp P. Controversies concerning the role of pendrin as an apical iodide transporter in thyroid follicular cells. Cellular Physiology And Biochemistry: International Journal Of Experimental Cellular Physiology, Biochemistry, And Pharmacology 2011; 28.3: 485-490

7 Bizzaro G, Shoenfeld Y. Vitamin D and thyroid autoimmune diseases: the known and the obscure. Immunol Res 2015; 61.1-2: 107-109

8 Bouillon R. Vitamin D and extraskeletal health. UpToDate October 29, 2014 2014. Web. December 4 2014;

9 Bouillon R, Muls E, De Moor P. Influence of thyroid function on the serum concentration of 1,25-dihydroxyvitamin D3. J Clin Endocrinol Metab 1980; 51.4: 793-797

10 Bozkurt NC, Karbek B, Ucan B et al. The association between severity of vitamin D deficiency and Hashimoto's thyroiditis. Endocr Pract 2013; 19.3: 479-484

11 Camurdan OM, Doger E, Bideci A et al. Vitamin D status in children with Hashimoto thyroiditis. J Pediatr Endocrinol Metab 2012; 25.56: $467-470$

12 Chailurkit LO, Aekplakorn W, Ongphiphadhanakul B. High vitamin D status in younger individuals is associated with low circulating thyrotropin. Thyroid 2013; 23.1: 25-30

13 Chailurkit LO, Aekplakorn W, Ongphiphadhanakul B. High vitamin D status in younger individuals is associated with low circulating thyrotropin. Thyroid: Official Journal Of The American Thyroid Association 2013; 23.1: 25-30

14 Chen W, Lin H, Wang M. Immune intervention effects on the induction of experimental autoimmune thyroiditis. J Huazhong Univ Sci Technolog Med Sci 2002; 22.4: 343-345 354

15 Choi YM, Kim WG, Kim TY et al. Low levels of serum vitamin D3 are associated with autoimmune thyroid disease in pre-menopausal women. Thyroid 2014; 24.4: 655-661

16 Clinckspoor I, Hauben E, Verlinden L et al. Altered expression of key players in vitamin D metabolism and signaling in malignant and benign thyroid tumors. J Histochem Cytochem 2012; 60.7: 502-511

17 Clinckspoor I, Verlinden L, Mathieu C et al. Vitamin D in thyroid tumorigenesis and development. Prog Histochem Cytochem 2013; 48.2: 65-98

18 Clinckspoor I, Verlinden L, Overbergh L et al. 1,25-dihydroxyvitamin D3 and a superagonistic analog in combination with paclitaxel or suberoylanilide hydroxamic acid have potent antiproliferative effects on anaplastic thyroid cancer. J Steroid Biochem Mol Biol 2011; 124.1-2: 1-9

19 D'Aurizio F, Villalta D, Metus $P$ et al. Is vitamin D a player or not in the pathophysiology of autoimmune thyroid diseases? Autoimmun Rev 2014

20 Demir K, Keskin M, Kor Y et al. Autoimmune thyroiditis in children and adolescents with type 1 diabetes mellitus is associated with elevated IgG4 but not with low vitamin D. Hormones (Athens) 2014; 13.3: 361-368

21 Effraimidis G, Badenhoop K, Tijssen JG et al. Vitamin D deficiency is not associated with early stages of thyroid autoimmunity. Eur J Endocrinol 2012; 167.1: 43-48

22 Effraimidis G, Wiersinga WM. Mechanisms in endocrinology: autoimmune thyroid disease: old and new players. Eur J Endocrinol 2014; 170.6: R241-R252

23 Feng $M$, Li H, Chen SF et al. Polymorphisms in the vitamin D receptor gene and risk of autoimmune thyroid diseases: a meta-analysis. Endocrine 2013; 43.2: 318-326

24 Fournier C, Gepner $P$, Sadouk $M$ et al. In vivo beneficial effects of cyclosporin A and 1,25-dihydroxyvitamin D3 on the induction of experimental autoimmune thyroiditis. Clin Immunol Immunopathol 1990; 54.1: 53-63

25 Goswami R, Marwaha RK, Gupta $N$ et al. Prevalence of vitamin D deficiency and its relationship with thyroid autoimmunity in Asian Indians: a community-based survey. Br J Nutr 2009; 102.3: 382-386

26 Grant WB. Ecological studies of the UVB-vitamin D-cancer hypothesis. Anticancer Res 2012; 32.1: 223-236

27 Grant WB. Hypothesis - ultraviolet-B irradiance and vitamin D reduce the risk of viral infections and thus their sequelae, including autoimmune diseases and some cancers. Photochem Photobiol 2008; 84.2: 356-365

28 Holick MF. Vitamin D deficiency. N Engl J Med 2007; 357.3: 266-281

29 Inoue $N$, Watanabe $M$, Ishido $N$ et al. The functional polymorphisms of VDR, GC and CYP2R1 are involved in the pathogenesis of autoimmune thyroid diseases. Clin Exp Immunol 2014; 178.2: 262-269

30 Jastrup B, Mosekilde L, Melsen $F$ et al. Serum levels of vitamin D metabolites and bone remodelling in hyperthyroidism. Metabolism 1982; 31.2: 126-132

31 Jones $G$. Extrarenal vitamin D activation and interactions between vitamin $\mathrm{D}(2)$, vitamin $\mathrm{D}(3)$, and vitamin $\mathrm{D}$ analogs. Annu Rev Nutr 2013; 33: 23-44 
32 Jonklaas J, Danielsen $M$, Wang $H$. A pilot study of serum selenium, vitamin $\mathrm{D}$, and thyrotropin concentrations in patients with thyroid cancer. Thyroid 2013; 23.9: 1079-1086

33 Kawakami-Tani T, Fukawa E, Tanaka $H$ et al. Effect of 1 alpha-hydroxyvitamin D3 on serum levels of thyroid hormones in hyperthyroid patients with untreated Graves' disease. Metabolism 1997; 46.10: $1184-1188$

34 Khadzkou K, Buchwald P, Westin G et al. 25-hydroxyvitamin D3 1alpha-hydroxylase and vitamin $D$ receptor expression in papillary thyroid carcinoma. J Histochem Cytochem 2006; 54.3: 355-361

$35 \mathrm{Kim}$ JR, Kim BH, Kim SM et al. Low serum 25 hydroxyvitamin d is associated with poor clinicopathologic characteristics in female patients with papillary thyroid cancer. Thyroid 2014; 24.11: 1618-1624

36 Kivity S, Agmon-Levin N, Zisappl M et al. Vitamin D and autoimmune thyroid diseases. Cell Mol Immunol 2011; 8.3: 243-247

37 Krysiak R, Kowalska B, Okopien B. Serum 25-Hydroxyvitamin D and parathyroid hormone levels in non-lactating women with postpartum thyroiditis: The effect of L-Thyroxine treatment. Basic Clin Pharmacol Toxicol 2014

38 Kurylowicz A, Badenhoop K. CYP27B1 gene polymorphism is associated with Graves' disease in a Polish population study. Thyroid 2005; 15.9: $1107-1108$

39 Kurylowicz A, Ramos-Lopez E, Bednarczuk T et al. Vitamin D-binding protein (DBP) gene polymorphism is associated with Graves' disease and the vitamin D status in a Polish population study. Exp Clin Endocrinol Diabetes 2006; 114.6: 329-335

40 Laney N, Meza J, Lyden E et al. The Prevalence of Vitamin D Deficiency Is Similar between Thyroid Nodule and Thyroid Cancer Patients. Int J Endocrinol 2010; 2010: 805716

41 Lin WY, Wan L, Tsai CH et al. Vitamin D receptor gene polymorphisms are associated with risk of Hashimoto's thyroiditis in Chinese patients in Taiwan. J Clin Lab Anal 2006; 20.3: 109-112

42 Liu S, Xiong F, Liu EM et al. Effects of 1,25-dihydroxyvitamin D3 in rats with experimental autoimmune thyroiditis. Nan Fang Yi Ke Da Xue Xue Bao 2010; 30.7: 1573-1576

43 Liu W, Asa SL, Fantus IG et al. Vitamin D Arrests Thyroid Carcinoma Cell Growth and Induces p27 Dephosphorylation and Accumulation through PTEN/Akt-Dependent and -Independent Pathways. Am J Pathol 2002; 160.2: 511-519

44 Lizis-Kolus K, Hubalewska-Dydejczyk A, Trofimiuk-Muldnerz $M$ et al. Assessment of 25(OH)D3, concentration levels in patients with papillary thyroid cancer compared to patients with Hashimoto's thyroiditis. Przegl Lek 2013; 70.11: 920-925

45 Lopez ER, Zwermann O, Segni $M$ et al. A promoter polymorphism of the CYP27B1 gene is associated with Addison's disease, Hashimoto's thyroiditis, Graves' disease and type 1 diabetes mellitus in Germans. Eur J Endocrinol 2004; 151.2: 193-197

46 MacFarlane IA, Mawer EB, Berry J et al. Vitamin D metabolism in hyperthyroidism. Clin Endocrinol (Oxf) 1982; 17.1: 51-59

47 Mackawy AM, Al-Ayed BM, Al-Rashidi BM. Vitamin d deficiency and its association with thyroid disease. Int J Health Sci (Qassim) 2013; 7.3: $267-275$

48 Mansournia N, Mansournia MA, Saeedi S et al. The association between serum 250HD levels and hypothyroid Hashimoto's thyroiditis. J Endocrinol Invest 2014; 37.5: 473-476

49 Morand GB, da Silva SD, Hier MP et al. Insights into Genetic and Epigenetic Determinants with Impact on Vitamin D Signaling and Cancer Association Studies: The Case of Thyroid Cancer. Front Oncol 2014; 4: 309

50 Muscogiuri G, Mitri J, Mathieu C et al. Mechanisms in endocrinology: vitamin $\mathrm{D}$ as a potential contributor in endocrine health and disease. Eur J Endocrinol 2014; 171.3: R101-R110

51 Pani MA, Regulla K, Segni $M$ et al. A polymorphism within the vitamin D-binding protein gene is associated with Graves' disease but not with Hashimoto's thyroiditis. The Journal Of Clinical Endocrinology And Metabolism 2002; 87.6: 2564-2567

52 Pani MA, Regulla K, Segni M et al. Vitamin D 1alpha-hydroxylase (CYP1alpha) polymorphism in Graves' disease, Hashimoto's thyroiditis and type 1 diabetes mellitus. European Journal Of Endocrinology/European Federation Of Endocrine Societies 2002; 146.6: 777-781

53 Penna-Martinez M, Ramos-Lopez E, Stern J et al. Vitamin D receptor polymorphisms in differentiated thyroid carcinoma. Thyroid 2009; 19.6: $623-628$

54 Penna-Martinez M, Ramos-Lopez E, Stern J et al. Impaired vitamin D activation and association with CYP24A1 haplotypes in differentiated thyroid carcinoma. Thyroid 2012; 22.7: 709-716
55 Pludowski P, Holick MF, Pilz S et al. Vitamin D effects on musculoskeletal health, immunity, autoimmunity, cardiovascular disease, cancer, fertility, pregnancy, dementia and mortality - a review of recent evidence. Autoimmun Rev 2013; 12.10: 976-989

56 Prietl B, Treiber G, Pieber TR et al. Vitamin D and immune function. Nutrients 2013; 5.7: 2502-2521

57 Roskies M, Dolev Y, Caglar D et al. Vitamin D deficiency as a potentially modifiable risk factor for thyroid cancer. J Otolaryngol Head Neck Surg 2012; 41.3: 160-163

58 Ross DS. Thyroid hormone synthesis and physiology. UpToDate. 2015; Web

59 Rotondi $M$, Chiovato $L$. Vitamin D deficiency in patients with Graves disease: probably something more than a casual association. Endocrine 2013; 43.1: 3-5

60 Sahin M, Ucan B, Ginis $Z$ et al. Vitamin D3 levels and insulin resistance in papillary thyroid cancer patients. Med Oncol 2013; 30.2: 589

61 Schottker B, Haug $U$, Schomburg $L$ et al. Strong associations of 25-hydroxyvitamin D concentrations with all-cause, cardiovascular, cancer, and respiratory disease mortality in a large cohort study. Am J Clin Nutr 2013; 97.4: 782-793

62 Sharma $V$, Fretwell $D$, Crees $Z$ et al. Thyroid cancer resistance to vitamin $D$ receptor activation is associated with 24-hydroxylase levels but not the ff FokI polymorphism. Thyroid 2010; 20.10: 1103-1111

63 Shin DY, Kim KJ, Kim D et al. Low serum vitamin D is associated with anti-thyroid peroxidase antibody in autoimmune thyroiditis. Yonsei Med J 2014; 55.2: 476-481

64 Speeckaert M, Huang G, Delanghe JR et al. Biological and clinical aspects of the vitamin $\mathrm{D}$ binding protein (Gc-globulin) and its polymorphism. Clin Chim Acta 2006; 372.1-2: 33-42

65 Stefanic M, Karner I, Glavas-Obrovac L et al. Association of vitamin D receptor gene polymorphism with susceptibility to Graves' disease in Eastern Croatian population: case-control study. Croat Med J 2005; 46.4: 639-646

66 Stepien T, Krupinski R, Sopinski J et al. Decreased 1-25 dihydroxyvitamin D3 concentration in peripheral blood serum of patients with thyroid cancer. Arch Med Res 2010; 41.3: 190-194

67 Stocklin E, Eggersdorfer M. Vitamin D, an essential nutrient with versatile functions in nearly all organs. Int J Vitam Nutr Res 2013; 83.2: $92-100$

68 SzczeklikA, Augustynowicz-Kopeć E. Choroby wewnętrzne: stan wiedzy na rok 2011.Kraków: Medycyna Praktyczna; 20112011

69 Theodoratou E, Tzoulaki I, Zgaga L et al. Vitamin D and multiple health outcomes: umbrella review of systematic reviews and meta-analyses of observational studies and randomised trials. BMJ 2014; 348: g2035

70 Unal $A D$, Tarcin 0 , Demirag $N G$ et al. Vitamin D deficiency is related to thyroid antibodies in autoimmune thyroiditis. Central European Journal of Immunology 2014; 39.4: 493-497

71 Wacker M, Holick MF. Sunlight and Vitamin D: A global perspective for health. Dermatoendocrinol 2013; 5.1: 51-108

$72 \mathrm{Xu} \mathrm{Y}, \mathrm{He} B$, Pan Y et al. Systematic review and meta-analysis on vitamin D receptor polymorphisms and cancer risk. Tumour Biol 2014; 35.5: 4153-4169

73 Yasuda T, Okamoto Y, Hamada $N$ et al. Serum vitamin D levels are decreased and associated with thyroid volume in female patients with newly onset Graves' disease. Endocrine 2012; 42.3: 739-741

74 Yasuda T, Okamoto $Y$, Hamada $N$ et al. Serum vitamin D levels are decreased in patients without remission of Graves' disease. Endocrine 2013; 43.1: 230-232

75 Yazici D, Yavuz D, Tarcin 0 et al. Vitamin D receptor gene ApaI, TaqI, FokI and BsmI polymorphisms in a group of Turkish patients with Hashimoto's thyroiditis. Minerva Endocrinol 2013; 38.2: 195-201

76 Yin K, Agrawal DK. Vitamin D and inflammatory diseases. Journal Of Inflammation Research 2014; 7: 69-87

77 Zhang $H$, Liang L, Xie Z. Low vitamin D status is associated with increased titers of thyroid stimulating hormone receptor antibodies in Graves' disease. Endocr Pract 2014; 1-23

78 Zhang LR, Sawka AM, Adams L et al. Vitamin and mineral supplements and thyroid cancer: a systematic review. Eur J Cancer Prev 2013; 22.2 : 158-168

79 Zhang $Q$ Wang Z, Sun $M$ et al. Association of high vitamin D status with low circulating thyroid-stimulating hormone independent of thyroid hormone levels in middle-aged and elderly males. Int J Endocrinol 2014; Epub $2014 \mathrm{Feb}$

80 Zhou H, Xu C, Gu M. Vitamin D receptor (VDR) gene polymorphisms and Graves' disease: a meta-analysis. Clin Endocrinol (Oxf) 2009; 70.6: 938-945

81 Zou M, BinHumaid FS, Alzahrani AS et al. Increased CYP24A1 expression is associated with BRAF(V600E) mutation and advanced stages in papillary thyroid carcinoma. Clin Endocrinol (Oxf) 2014; 81.1: 109-116 